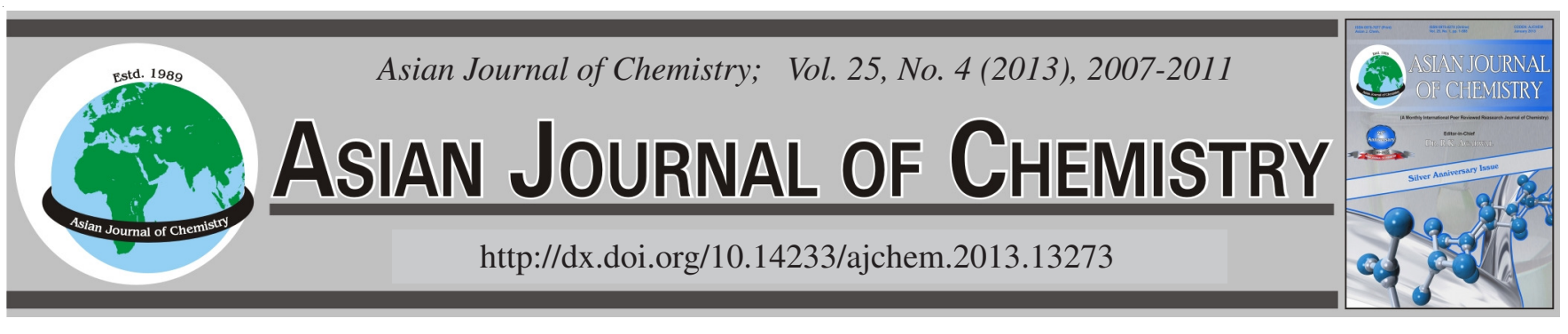

\title{
Solubility Studies of Haloglycine by Quantum Mechanical Method
}

\author{
S. Sampath Krishnan ${ }^{1, *}$, N. Balamurugan ${ }^{2}$, R. Kumutha ${ }^{3}$ and S. Mahalakshmi ${ }^{4}$
}

\begin{abstract}
${ }^{1}$ Department of Applied Physics, Sri Venkateswara College of Engineering, Sriperumbudur-602 105, India
${ }^{2}$ Department of Physics, PERI Institute of Technology, Chennai-600 048, India

${ }^{3}$ Department of Physics, Jaya Engineering College, Thiruninravur, Chennai-602 024, India

${ }^{4}$ Department of Physics, Aarupadai Veedu Institute of Technology, Chennai-603 104, India
\end{abstract}

*Corresponding author: Fax: +91 44 27162462; Tel: +91 44 2715200; E-mail: sambathk@svce.ac.in

\section{INTRODUCTION}

An new materials, quantum mechanical solvation analysis can be applied for electron structure calculation. Zwitterions salt of glycine has neutral $\mathrm{pH}$ which can be used for optical communication, optical computing, optical information processing, optical disk data storage, laser fusion reactions, laser remote sensing, colour display medical diagnostics, glycine used sold as a sweetening enhancer. Food supplement and protein drinks contain glycine. Certain drug formulations include glycine to improve gastric absorption of the drug. Glycine serves as a buffering agent in antacids, analgesics, antiperspirants, cosmetics and toiletries. Many miscellaneous products such as use glycine \& its derivatives rubber sponge products, fertilizers and metals complexants.

Hydrobromic acid is mainly used for the production of inorganic bromides, especially the bromides of zinc, calcium and sodium. It is a useful reagent for generating organobromine compounds. Industrially significant organic compounds are prepared from hydrobromic acid including allyl bromide, tetrabromide and bromoacetic acid.

Hydrochloric acid is used for large number of small scale applications, such as leather processing, purification of common salt, household cleaning and building construcation. Oil production may be stimulated by injecting hydrochloric acid into the rock formation of an oil well to dissolve a portion of the rock and to creat a large pore structure. Oil well acidizing is a common process in the North sea oil production industry.
Many chemical reactions involving hydrochloric acid are applied in the production of food, food ingredients and food additives ${ }^{1,2}$. Combined quantum mechanical and molecular mechanical potential coupled with Monte Carlo or molecular dynamics simulations offer the opportunity to study chemical processes in solutions and in enzymes ${ }^{3-5}$. The theoretical study of solvation is difficult for large molecules involved, with the difficulty proceeding from the problem of the simultaneous evaluation of their mutual interactions. This can be solved using solvation technology.

\section{COMPUTATIONAL METHOD}

The conformational analysis is done using a wide range of polar and non polar solvents, which has been performed both in the gas phase and in the solvent medium of various dielectric constants using polarized continuum Model (PCM) by STO-6-31 basis set to interpret the solvent effect of the molecules. The computer program GAMESS Gamess Schmidt was used for this purpose ${ }^{6}$.

\section{RESULTS AND DISCUSSION}

Electrostatic contributions in free energy: The solvation effects of haloglycine are investigated for the most stable conformers of each haloglycine. The calculation of free energy electrostatic interaction, dispersion energy, repulsion energy and cavitation enthalpies of three haloglycine in different solvents are calculated by polarized continuum Model (PCM). 
TABLE-1

FREE ENERGY OF HALOGLYCINE AND ITS DERIVATIVES IN kcal/mol

\begin{tabular}{ccccc}
\hline Solvents & Glycine & Fluoro glycine & Chloro glycine & Bromo glycine \\
\hline & -177403.33 & Polar & -1791748.14 \\
\hline $\mathrm{H}_{2} \mathrm{O}$ & -177403.14 & -240130.60 & -466074.39 & -1791747.86 \\
$\mathrm{CH}_{3} \mathrm{OH}$ & -177403.03 & -240130.21 & -466074.07 & -1791747.71 \\
$\mathrm{C}_{2} \mathrm{H}_{5} \mathrm{OH}$ & -177402.28 & -240130.00 & -466073.07 & -1791746.63 \\
$\mathrm{CH}_{2} \mathrm{CL}_{2}$ & -177401.94 & -240128.49 & -466072.63 & -1791746.13 \\
$\mathrm{C}_{6} \mathrm{H}_{5} \mathrm{NH}_{2}$ & -177402.08 & -240127.80 & -466072.05 & -1791746.33 \\
$\mathrm{THF}$ & -177403.24 & -240128.07 & -466072.28 & -1791748.01 \\
$\mathrm{DMSO}$ & -240130.41 & -466074.23 & -1791745.26 \\
\hline & -177401.33 & Non-polar & -1791741.73 \\
$\mathrm{CHCL}_{3}$ & -177398.88 & -240126.58 & -466071.02 & -1791741.79 \\
$\mathrm{CCL}_{4}$ & -177398.91 & -240121.67 & -466066.92 & -1791742.14 \\
$\mathrm{C}_{6} \mathrm{H}_{6}$ & -177399.16 & -240121.74 & -466066.98 & -1791745.65 \\
$\mathrm{C}_{6} \mathrm{H}_{5} \mathrm{CH}_{3}$ & -177401.60 & -240121.23 & -466067.39 & -1791747.93 \\
$\mathrm{C}_{6} \mathrm{H}_{5} \mathrm{CL}$ & -177403.19 & -240127.12 & -466071.48 & -1791740.73 \\
$\mathrm{CH}_{3} \mathrm{NO}_{2}$ & -177398.14 & -240130.31 & -466074.15 & -1791741.10 \\
$\mathrm{C}_{7} \mathrm{H}_{16}$ & -177398.43 & -240120.27 & -466065.75 & -466066.18 \\
$\mathrm{C}_{6} \mathrm{H}_{12}$ & -240120.78 & & \\
\hline
\end{tabular}

These quantities typically converge quickly during a simulation and thus can provide a good assessment of computational approaches in describing solvent-solute interaction ${ }^{7}$. A set of polar and non-polar solvent like water, methanol, ethanol, chloroform, aniline, tetrahydrofuran, dimethyl sulfoxide, chloroform, carbon tetra chloride, benzene, toluene, chlorobenzene, nitromethane, $n$-heptane and cyclohexane were used for this solvation analysis (Table-1, Fig. 1).

The electrostatic interaction contribution to free energy depends on the dielectric constant of the solvent ${ }^{8}$. The electrostatic contribution to the total solvation energy is maximum for the three haloglycine in methanol This may be due to the dielectric constant of methanol It is least in benzene among the aprotic solvents. However in protic solvents, the electrostatic contribution does not correlate with the dielectric constant because the protic solvent is associated through intermolecular hydrogen bonds.

The trend in the electrostatic energy can be explained as follows. Among the haloglycine, $\mathrm{HF}$ is the most electronegative atom and hence the electrostatic interaction is large. Bromine is less electronegative and the interaction is also less. However, Fluoro glycine is a large atom and its polarizability is large ${ }^{9}$ (Table-2, Fig. 2).

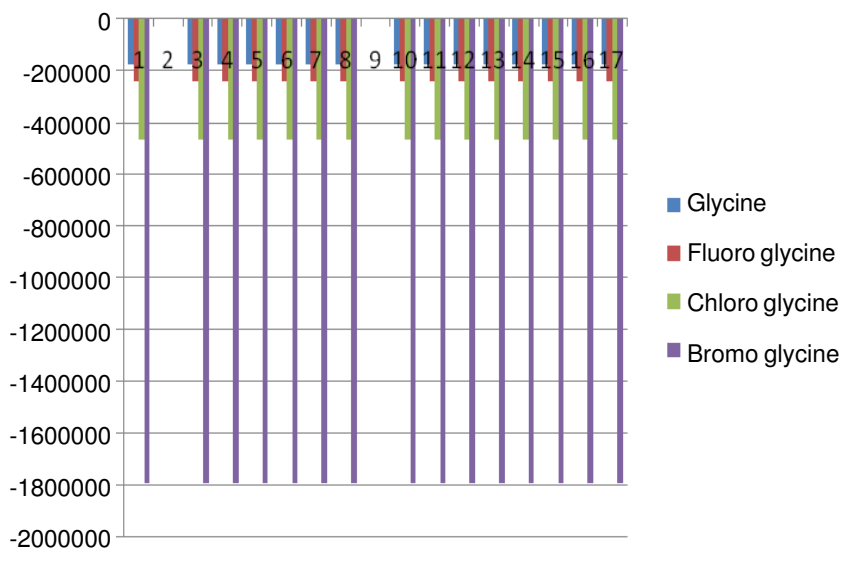

Fig. 1. Free energy of haloglycine

\begin{tabular}{|c|c|c|c|c|}
\hline \multicolumn{5}{|c|}{$\begin{array}{c}\text { TABLE-2 } \\
\text { ELECTROSTATIC INTERACTION OF } \\
\text { HALOGLYCINE AND ITS DERIVATIVES IN kcal/mol }\end{array}$} \\
\hline Solvents & Glycine & $\begin{array}{l}\text { Fluoro } \\
\text { glycine }\end{array}$ & $\begin{array}{l}\text { Chloro } \\
\text { glycine }\end{array}$ & $\begin{array}{l}\text { Bromo } \\
\text { glycine }\end{array}$ \\
\hline \multicolumn{5}{|c|}{ Polar } \\
\hline $\mathrm{H}_{2} \mathrm{O}$ & -10.48 & -21.17 & -17.74 & -15.15 \\
\hline $\mathrm{CH}_{3} \mathrm{OH}$ & -10.25 & -20.71 & -17.35 & -14.82 \\
\hline $\mathrm{C}_{2} \mathrm{H}_{5} \mathrm{OH}$ & -10.13 & -20.44 & -17.13 & -14.63 \\
\hline $\mathrm{CH}_{2} \mathrm{Cl}_{2}$ & -9.25 & -18.64 & -15.60 & -13.35 \\
\hline $\mathrm{C}_{6} \mathrm{H}_{5} \mathrm{NH}_{2}$ & -8.86 & -17.81 & -14.91 & -12.76 \\
\hline THF & -9.01 & -18.14 & -15.19 & -13.00 \\
\hline DMSO & -10.37 & -20.94 & -17.55 & -14.99 \\
\hline \multicolumn{5}{|c|}{ Non-polar } \\
\hline $\mathrm{CHCl}_{3}$ & -8.16 & -16.38 & -13.70 & -11.74 \\
\hline $\mathrm{CCL}_{4}$ & -5.42 & -10.78 & -9.00 & -7.76 \\
\hline $\mathrm{C}_{6} \mathrm{H}_{6}$ & -5.46 & -10.87 & -9.07 & -7.81 \\
\hline $\mathrm{C}_{6} \mathrm{H}_{5} \mathrm{CH}_{3}$ & -5.73 & -11.41 & -9.53 & -8.20 \\
\hline $\mathrm{C}_{6} \mathrm{H}_{5} \mathrm{Cl}$ & -8.47 & -17.01 & -14.24 & -12.19 \\
\hline $\mathrm{CH}_{3} \mathrm{NO}_{2}$ & -10.31 & -20.82 & -17.45 & -14.90 \\
\hline $\mathrm{C}_{7} \mathrm{H}_{16}$ & -4.65 & -9.24 & -7.71 & -6.65 \\
\hline $\mathrm{C}_{6} \mathrm{H}_{12}$ & -4.93 & -9.80 & -8.18 & -7.05 \\
\hline
\end{tabular}

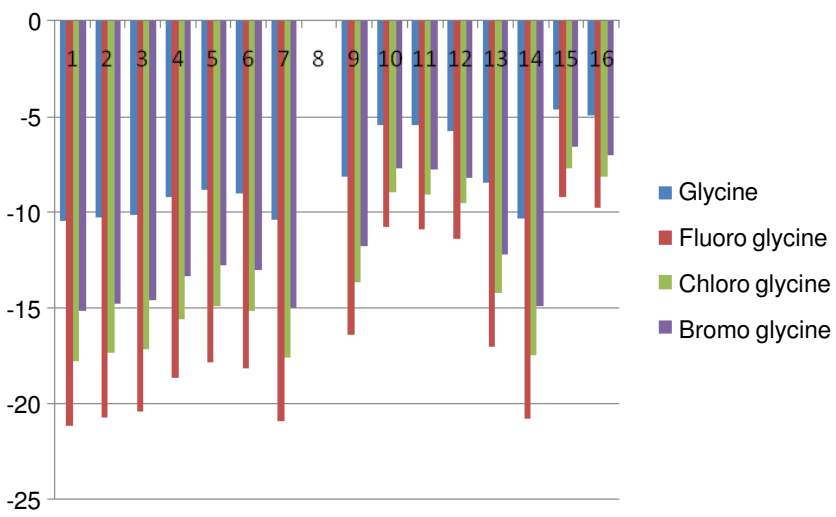

Fig. 2. Electrostatic interaction of haloglycine

Dispersion energy: The dispersion energy term is often collected with the repulsion term into a unique term defining the so-called van der Waals contribution to the interaction energy (Table-3, Fig. 3). 


\begin{tabular}{|c|c|c|c|c|}
\hline \multicolumn{5}{|c|}{$\begin{array}{c}\text { TABLE-3 } \\
\text { DISPERSION ENERGY OF SOLVATION OF } \\
\text { HALOGLYCINE IN VARIOUS SOLVENTS kcal/mol }\end{array}$} \\
\hline Solvents & Glycine & $\begin{array}{l}\text { Fluoro } \\
\text { glycine }\end{array}$ & $\begin{array}{l}\text { Chloro } \\
\text { glycine }\end{array}$ & $\begin{array}{l}\text { Bromo } \\
\text { glycine }\end{array}$ \\
\hline \multicolumn{5}{|c|}{ Polar } \\
\hline $\mathrm{H}_{2} \mathrm{O}$ & -13.254 & -12.239 & -11.813 & -11.719 \\
\hline $\mathrm{CH}_{3} \mathrm{OH}$ & -13.254 & -12.239 & -11.813 & -11.719 \\
\hline $\mathrm{C}_{2} \mathrm{H}_{5} \mathrm{OH}$ & -13.254 & -12.239 & -11.813 & -11.719 \\
\hline $\mathrm{CH}_{2} \mathrm{Cl}_{2}$ & -13.254 & -12.239 & -11.813 & -11.719 \\
\hline $\mathrm{C}_{6} \mathrm{H}_{5} \mathrm{NH}_{2}$ & -13.254 & -12.239 & -11.813 & -11.719 \\
\hline THF & -13.254 & -12.239 & -11.813 & -11.719 \\
\hline DMSO & -13.254 & -12.239 & -11.813 & -11.719 \\
\hline \multicolumn{5}{|c|}{ Non-polar } \\
\hline $\mathrm{CHCl}_{3}$ & -13.254 & -12.239 & -11.813 & -11.719 \\
\hline $\mathrm{CCL}_{4}$ & -13.254 & -12.239 & -11.813 & -11.719 \\
\hline $\mathrm{C}_{6} \mathrm{H}_{6}$ & -13.254 & -12.239 & -11.813 & -11.719 \\
\hline $\mathrm{C}_{6} \mathrm{H}_{5} \mathrm{CH}_{3}$ & -13.254 & -12.239 & -11.813 & -11.719 \\
\hline $\mathrm{C}_{6} \mathrm{H}_{5} \mathrm{Cl}$ & -13.254 & -12.239 & -11.813 & -11.719 \\
\hline $\mathrm{CH}_{3} \mathrm{NO}_{2}$ & -13.254 & -12.239 & -11.813 & -11.719 \\
\hline $\mathrm{C}_{7} \mathrm{H}_{16}$ & -13.254 & -12.239 & -11.813 & -11.719 \\
\hline $\mathrm{C}_{6} \mathrm{H}_{12}$ & -13.254 & -12.239 & -11.813 & -11.719 \\
\hline
\end{tabular}

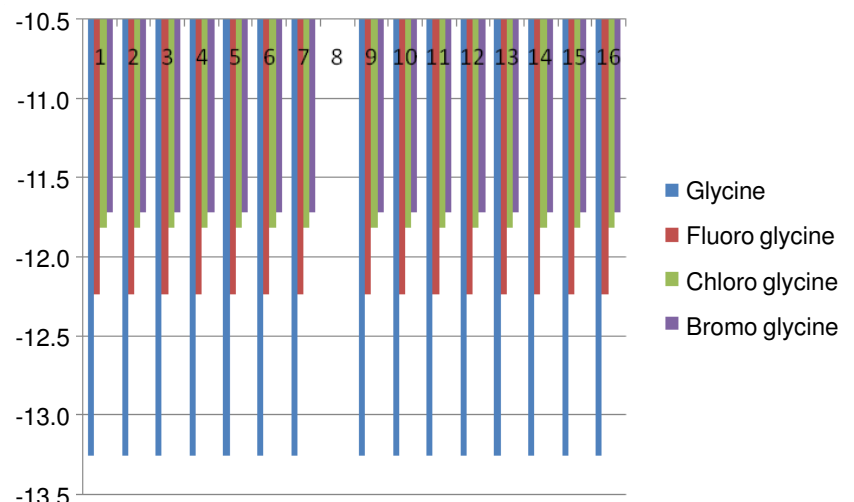

Fig. 3. Dispersion energy of solvation of haloglycine

The method implemented in PCM is based on the formulation of the theory given by McWeeny and on the use of dynamic polarizabilities.

The final formula of the solute solvent dispersion free energy in the usual framework of a molecular orbital description of the wave function reads

$$
\mathrm{G}=-\frac{\beta}{2} \sum\left(\frac{\mathrm{rs}}{\mathrm{tu}}\right) \mathrm{P}(\mathrm{S})+-\frac{\beta}{4} \sum\left(\frac{\mathrm{rs}}{\mathrm{tu}}\right) \mathrm{PP}
$$

where the subscripts refer to the elements of the selected basis set $\{\mathrm{X}\}$. The term $[\mathrm{rs}]$ and $[\mathrm{tu}]$ has the aspect of a two-electron integral, but simply involves combinations of one-electron integrals in the following way.

$$
\left(\frac{\mathrm{rs}}{\mathrm{tu}}\right)=\frac{1}{2} \int \mathrm{d} \overrightarrow{(\mathrm{s})}[\mathrm{V} \overrightarrow{(\mathrm{s})} \mathrm{E} \overrightarrow{(\mathrm{s})}+\mathrm{V} \overrightarrow{(\mathrm{s})} \mathrm{E} \overrightarrow{(\mathrm{s})}]
$$

where the integration is done on the cavity surface and $\mathrm{V}$ and E represent the potential and the normal component of the electric field computed at the same point surface when expressed on the chosen basis set by Mahalakshmi et al. ${ }^{10}$.

The $\mathrm{P}$ coefficients in equation for $\mathrm{G}$ are elements of the first order solute density matrix $\mathrm{P}$ expressed in the same basis set. $\mathrm{S}$ is the overlap matrix in the same basis and has the expression.

$$
\beta=\frac{(\mathrm{n}-1)}{4 \pi \mathrm{n}(\mathrm{n}+)}
$$

where $\mathrm{n}$ is the refractive index of the solvent, I its first ionization potential and the solute average transition energy. Expression $\mathrm{G}$ may be rewritten in a matrix form, making use, once again of the trace operator and introducing two new matrices with integrals performed over the basis set

$$
\mathrm{G}=\operatorname{tr} \mathrm{P}\left[\frac{\mathrm{h}+}{\mathrm{x}(\mathrm{P})}\right]
$$

where the elements of the two matrices we have here introduced have the following form:

$$
\begin{gathered}
(\mathrm{h})=-\frac{\beta}{2} \sum\left(\frac{\mathrm{rs}}{\mathrm{tu}}\right)(\mathrm{S}) \\
(\mathrm{X})=\frac{\beta}{2} \sum\left(\frac{\mathrm{rs}}{\mathrm{tu}}\right) \mathrm{P}
\end{gathered}
$$

The integrals defining these matrix elements can be computed in a discrete form, making use of the tessellation of the cavity surface used to compute the apparent charges in PCM continuum methods. The nature of $\beta$ indicates the approximations introduced in this elaboration of the dispersion energy operators among them one is specific for the solute, the average transition energy. Because the most important transitions in polarization o molecules occur between "frontier" orbital's-the average transition energy can be approximated by defining a proper window around the energy of the highest occupied orbital.

The computational demand is higher for dispersion than repulsion as the basic integrals are more complex in the dispersion than repulsion as the basic integrals are more complex in the dispersion term, which also includes a second term $(\mathrm{X})$ not present in repulsion in addition, $\mathrm{G}$ turns out to be quite sensitive to the quality of the basis set to have good values of this quantity we need to use basis sets decidedly larger than those necessary for geometry optimization and for the calculations of the solvation energy.

The dispersion energies are due to polarization of the solvent molecules by the solute molecules ${ }^{11}$. This polarization, in turn, may depend on the dipole moment of the solvent molecule. From the data in Table-3, it is found that the dispersion energy of haloglycine is higher Which has a lower dipole moment. Thus the dispersion energy of haloglycine in different solvents may be correlated with the dipole moment of the solvent. However, there is not much change in the dispersion energies in protic solvents of varying dipole moment.

Repulsion energy: With PCM it is possible to collect all the charging processes into a single process, performed at the quantum mechanics level with the aid of an appropriate Schrodinger equation. This unique feature of PCM, that is, the unification of different processes into a single step (or, in other words, to treat repulsion, dispersion and electrostatic contributions on the same footing), considerably reduces the problem of couplings. In fact, in a series of different charging processes performed in sequence, one has to use, for the second process, the solvent distribution function modified by 
the first. There are couplings among charge processes that are neglected in this sequence and the final result depends to some extent on the chosen sequence of Mahalakshmi et al. ${ }^{10}$.

The theory for the repulsion term derives from the theory (Table-4, Fig. 4) of the exchange term as expressed in the perturbation theory treatment of no covalent interactions. Application of perturbation theories to the description of molecular interactions is quite complex problem and the main source of this complexity derives from the additional elements in the antisymmetry operator for the electronic wave function, which gives rise to the exchange terms. The difficulties quantum mechanics finds in describing a system $M$ interacting with others. An exact expression for exchange contributions to the interaction energy is not available. There are excellent approximations that have given good results for molecular systems of small dimensions and there is a hierarchy of descriptions introducing more and more simplifications and ending with very simple expressions. An example of this last level of accuracy is the $r$ term used in the Lennard-Jonnes site-site potential.

The expression used in PCM due to Amovilli and Mennucci is based on a dissection of the exchange energy for a dimmer into terms, depending on the electronic densities of the partners. The elaboration of this expression, derived for the interactions energy of two molecules, to get $G$ uses the replacement of the electron density of the second partner (the first is the solute) with a one-electron charge distribution averaged over the whole body of the solvent. When followed by proper mathematical manipulations, this elaboration reduces the double integral over the whole space to a simple integral of the solute charge distribution lying outside the cavity C multiplied by a constant factor given by Mahalakshmi et al. ${ }^{10}$.

$$
\begin{gathered}
\mathrm{G}=\alpha \int \rho(\overrightarrow{\mathrm{r}}) \mathrm{dr} \\
\alpha=\mathrm{k} \rho \frac{\mathrm{n}}{\mathrm{m}}
\end{gathered}
$$

where the subscript $M$ refers to the solute (and $\rho$ indicates its electronic density). S refers to the solvent. $\rho$ is the density of the solvent relative to density of water at $298 \mathrm{~K}$ and $\mathrm{n}$ and $\mathrm{M}$ are the number of valence electrons and the molecular weight of the solvent, respectively. The integral in the above equation which represents the portion of solute charge lying outside the cavity, is rewritten as the difference of total solute electronic charge inside the cavity. By applying the Gauss theorem, we obtain that the internal charge is $1 / 4 \pi \int E(s) n(s) d s$, where $n$ is the outward unit vector perpendicular to the cavity surface at point $\mathrm{s}$ and $\mathrm{E}$ the solute electric field due to the electrons only.

The repulsion energies of haloglycine in different solvents are given in Table-4 (Fig. 4). This value also indicates that he dielectric constant as well as the molecular size of the solvent molecules determine the repulsive energies. This is supported by the higher values of the repulsion energies of the haloglycine in chloroform compared to protic solvents chosen in the present investigation. It may be noted that the repulsion energies of the haloglycine in aqueous solution are much greater than those in methanol. This may be due to the slight attraction between methyl group and alkyl group of the

\begin{tabular}{|c|c|c|c|c|}
\hline \multicolumn{5}{|c|}{$\begin{array}{c}\text { TABLE-4 } \\
\text { REPULSION ENERGY OF SOLVATION OF } \\
\text { HALOGLYCINE IN VARIOUS SOLVENTS } \mathrm{kcal} / \mathrm{mol}\end{array}$} \\
\hline Solvents & Glycine & $\begin{array}{l}\text { Fluoro } \\
\text { glycine }\end{array}$ & $\begin{array}{l}\text { Chloro } \\
\text { glycine }\end{array}$ & $\begin{array}{l}\text { Bromo } \\
\text { glycine }\end{array}$ \\
\hline \multicolumn{5}{|c|}{ Polar } \\
\hline $\mathrm{H}_{2} \mathrm{O}$ & 2.10 & 1.82 & 1.73 & 1.74 \\
\hline $\mathrm{CH}_{3} \mathrm{OH}$ & 2.10 & 1.82 & 1.73 & 1.74 \\
\hline $\mathrm{C}_{2} \mathrm{H}_{5} \mathrm{OH}$ & 2.10 & 1.82 & 1.73 & 1.74 \\
\hline $\mathrm{CH}_{2} \mathrm{Cl}_{2}$ & 2.10 & 1.82 & 1.73 & 1.74 \\
\hline $\mathrm{C}_{6} \mathrm{H}_{5} \mathrm{NH}_{2}$ & 2.10 & 1.82 & 1.73 & 1.74 \\
\hline THF & 2.10 & 1.82 & 1.73 & 1.74 \\
\hline DMSO & 2.10 & 1.82 & 1.73 & 1.74 \\
\hline \multicolumn{5}{|c|}{ Non-polar } \\
\hline $\mathrm{CHCl}_{3}$ & 2.10 & 1.82 & 1.73 & 1.74 \\
\hline $\mathrm{CCL}_{4}$ & 2.10 & 1.82 & 1.73 & 1.74 \\
\hline $\mathrm{C}_{6} \mathrm{H}_{6}$ & 2.10 & 1.82 & 1.73 & 1.74 \\
\hline $\mathrm{C}_{6} \mathrm{H}_{5} \mathrm{CH}_{3}$ & 2.10 & 1.82 & 1.73 & 1.74 \\
\hline $\mathrm{C}_{6} \mathrm{H}_{5} \mathrm{Cl}$ & 2.10 & 1.82 & 1.73 & 1.74 \\
\hline $\mathrm{CH}_{3} \mathrm{NO}_{2}$ & 2.10 & 1.82 & 1.73 & 1.74 \\
\hline $\mathrm{C}_{7} \mathrm{H}_{16}$ & 2.10 & 1.82 & 1.73 & 1.74 \\
\hline $\mathrm{C}_{6} \mathrm{H}_{12}$ & 2.10 & 1.82 & 1.73 & 1.74 \\
\hline
\end{tabular}
haloglycine.

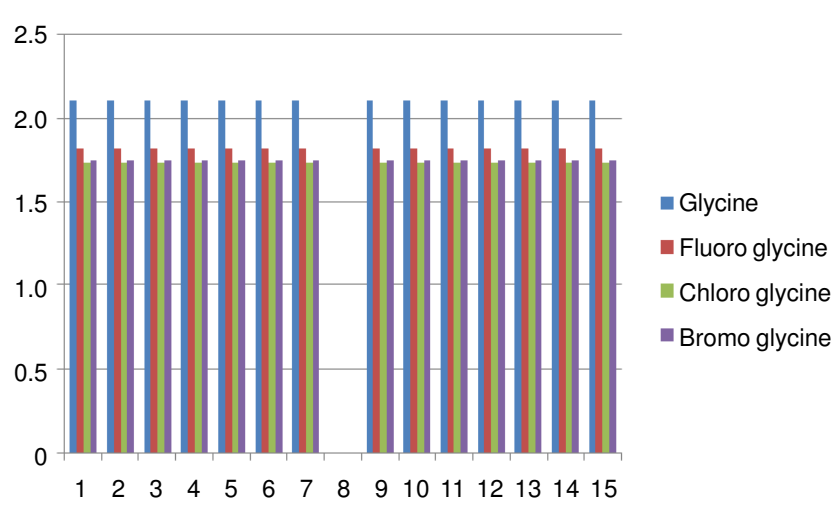

Fig. 4. Repulsion energy of solvation of haloglycine

Contribution of cavitation enthalpies: The cavitation enthalpies of molecules in different solutions are the measure of enthalpy contribution to the free energy of solvation ${ }^{12,13}$. There are several methods for the calculation of cavitation thermodynamic quantities these quantities in Table-5 (Fig. 5) obtained in the present calculations are expected to have reasonable accuracy from the formulas given by the microscopic surface tension method Sinanglu and Pierotti ${ }^{14}$. The cavitation enthalpies calculated by two methods give two different results. However, the trend is similar. Among aprotic solvents, the cavitation enthalpy has the highest positive values for all three systems in benzene thus the solvation of haloglycine in benzene is more endothermic than in the other aprotic solvents. In the case of protic solvents, this value is more positive in aqueous solution than in methanol which also indicates that there is weaker interaction between haloglycine in aqueous solution than in methanol. Thermodynamic quantityof microscopic cavity factor calculated at $298 \mathrm{~K}$ are given in Table-6 (Fig. 6).

\section{Conclusion}

The quantum mechanical solvation analyses have been carried out for haloglycine The computed physical properties such as free energy components, electrostatic interaction, dipole 
TABLE-5

CAVITATION ENTHALPIES OF SOLVATION OF HALOGLYCINE IN VARIOUS SOLVENTS kcal/mol

\begin{tabular}{|c|c|c|c|c|c|c|c|c|}
\hline \multirow{2}{*}{ Solvents } & \multicolumn{2}{|c|}{ Glycine } & \multicolumn{2}{|c|}{ Fluoro glycine } & \multicolumn{2}{|c|}{ Chloro glycine } & \multicolumn{2}{|c|}{ Bromo glycine } \\
\hline & Pierotti & Sinanoglu & Pierotti & Sinanoglu & Pierotti & Sinanoglu & Pierotti & Sinanoglu \\
\hline \multicolumn{9}{|c|}{ Polar } \\
\hline $\mathrm{H}_{2} \mathrm{O}$ & 1.43470 & 16.95441 & 1.60088 & 20.72067 & 1.73986 & 23.26795 & 1.80255 & 23.96890 \\
\hline $\mathrm{CH}_{3} \mathrm{OH}$ & 4.78852 & 7.91035 & 5.32730 & 9.32084 & 5.77743 & 10.24464 & 5.98035 & 10.50380 \\
\hline $\mathrm{C}_{2} \mathrm{H}_{5} \mathrm{OH}$ & 5.00418 & 7.79108 & 5.56454 & 9.17462 & 6.03264 & 10.11037 & 6.24364 & 10.36786 \\
\hline $\mathrm{CH}_{2} \mathrm{Cl}_{2}$ & 6.37714 & 0.89345 & 7.09038 & 1.54646 & 7.68618 & 1.98811 & 7.95474 & 2.10964 \\
\hline $\mathrm{C}_{6} \mathrm{H}_{5} \mathrm{NH}_{2}$ & 9.99689 & 8.96265 & 11.15015 & 11.5522 & 12.11465 & 12.63814 & 12.54972 & 13.04620 \\
\hline THF & 69.78920 & -0.28604 & 78.25529 & 0.38345 & 85.34903 & 0.83625 & 88.55239 & 0.96085 \\
\hline DMSO & 703.89294 & -23.06420 & 783.88458 & -49.08555 & 850.74488 & -66.68486 & 880.89373 & -71.52770 \\
\hline \multicolumn{9}{|c|}{ Non-polar } \\
\hline $\mathrm{CHCl}_{3}$ & 5.86860 & 0.53459 & 6.52129 & 1.18784 & 7.06642 & 1.62966 & 7.31212 & 1.75124 \\
\hline $\mathrm{CCl}_{4}$ & 6.57293 & 5.12168 & 7.30408 & 6.99476 & 7.91475 & 8.26160 & 8.18999 & 8.61020 \\
\hline $\mathrm{C}_{6} \mathrm{H}_{6}$ & 8.05479 & 5.66874 & 8.95753 & 7.69753 & 9.71175 & 9.06968 & 10.05174 & 9.44726 \\
\hline $\mathrm{C}_{6} \mathrm{H}_{5} \mathrm{CH}_{3}$ & 6.39125 & 5.58413 & 7.10500 & 7.57735 & 7.70124 & 8.92545 & 7.97001 & 9.29640 \\
\hline $\mathrm{C}_{6} \mathrm{H}_{5} \mathrm{Cl}$ & 6.64866 & -0.11093 & 7.39657 & 0.757735 & 8.02150 & 1.33626 & 8.30325 & 1.49693 \\
\hline $\mathrm{CH}_{3} \mathrm{NO}_{2}$ & 6.75734 & 9.49920 & 7.52257 & 12.05466 & 8.16207 & 13.78302 & 8.45040 & 14.25862 \\
\hline $\mathrm{C}_{7} \mathrm{H}_{16}$ & 5.84927 & 3.69893 & 6.48950 & 5.16457 & 7.02397 & 6.15584 & 7.26479 & 6.42861 \\
\hline $\mathrm{C}_{6} \mathrm{H}_{12}$ & 6.45825 & 4.55032 & 7.17593 & 6.33253 & 7.77535 & 7.53792 & 8.04552 & 7.86960 \\
\hline
\end{tabular}

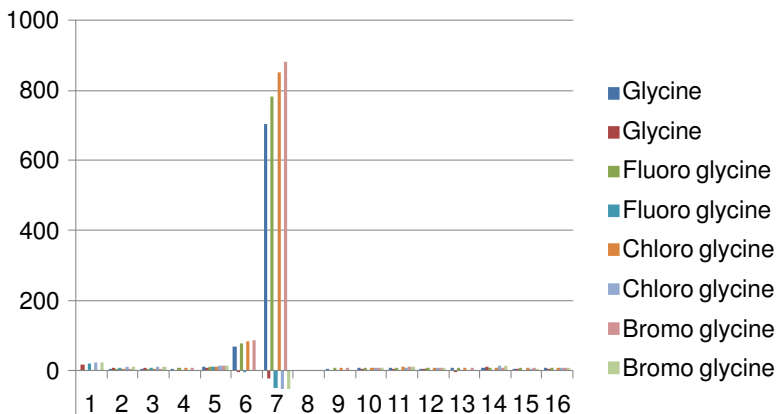

$-200$

Fig. 5. Thermodynamic quantity of cavitation enthalpies calculated at 298 $\mathrm{K}(\mathrm{kcal} / \mathrm{mol})$

TABLE-6

THERMODYNAMIC QUANTITY OF MICROSCOPIC CAVITY FACTOR CALCULATED AT $298 \mathrm{~K}(\mathrm{kcal} / \mathrm{mol})$

\begin{tabular}{lcccc}
\hline \multicolumn{1}{c}{ Solvents } & Glycine & $\begin{array}{c}\text { Fluoro } \\
\text { glycine }\end{array}$ & $\begin{array}{c}\text { Chloro } \\
\text { glycine }\end{array}$ & $\begin{array}{c}\text { Bromo } \\
\text { glycine }\end{array}$ \\
\hline & \multicolumn{5}{c}{ Polar } \\
\hline $\mathrm{H}_{2} \mathrm{O}$ & 1.277 & 1.277 & 1.277 & 1.277 \\
$\mathrm{CH}_{3} \mathrm{OH}$ & 1.776 & 1.766 & 1.776 & 1.766 \\
$\mathrm{C}_{2} \mathrm{H}_{5} \mathrm{OH}$ & 1.543 & 1.543 & 0 & 1.543 \\
$\mathrm{CH}_{2} \mathrm{Cl}_{2}$ & 0 & 0.972 & 0.972 & 0 \\
$\mathrm{C}_{6} \mathrm{H}_{5} \mathrm{NH}_{2}$ & 0.972 & 0 & 0 & 0.972 \\
$\mathrm{THF}$ & 0 & 0 & 0 & 0 \\
$\mathrm{DMSO}$ & 0 & 0 & 0 & 0 \\
\hline \multicolumn{5}{c}{ Non-polar } \\
\hline $\mathrm{CHCl}_{3}$ & 0 & 0 & 0 & 0 \\
$\mathrm{CCL}_{4}$ & 0.629 & 0.629 & 0.629 & 0.629 \\
$\mathrm{C}_{6} \mathrm{H}_{6}$ & 0.629 & 0.629 & 0.629 & 0.629 \\
$\mathrm{C}_{6} \mathrm{H}_{5} \mathrm{CH}_{3}$ & 0.679 & 0.679 & 0.679 & 0.679 \\
$\mathrm{C}_{6} \mathrm{H}_{5} \mathrm{Cl}$ & 0 & 0 & 0 & 0 \\
$\mathrm{CH}_{3} \mathrm{NO}_{2}$ & 0.808 & 0.808 & 0.808 & 0.808 \\
$\mathrm{C}_{7} \mathrm{H}_{16}$ & 0.687 & 0.687 & 0.687 & 0.687 \\
$\mathrm{C}_{6} \mathrm{H}_{12}$ & 0.621 & 0.621 & 0.621 & 0.621 \\
\hline
\end{tabular}

moments and induced dipole moments are discussed. The dipole moment values caused by solvent -solute interaction lead to a systematic increase in all molecules studied here. The interaction between the three haloglycine and various solvents are investigated to explain the condensed phase simulation, which will be useful for the study of solvation of the haloglycine.

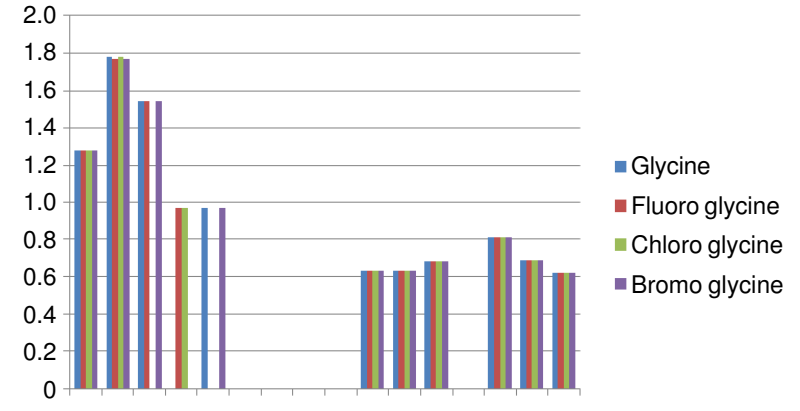

$122 \quad 3 \quad 4 \quad 5 \quad 6 \quad 7 \quad 8 \quad 910111213141516$

Fig. 6. Thermodynamic quantity of microscopic cavity factor calculated at $298 \mathrm{~K}(\mathrm{kcal} / \mathrm{mol})$

\section{ACKNOWLEDGEMENTS}

The authors thanks Thiru Sarav Periasamy, Chairman and Dr. S. Sandil Velan, Principal and Thiru Sasi Veerarajan, Chief Operating Officer, Peri Institute of Technology, Chennai for their encouragement throughout the work.

\footnotetext{
REFERENCES

1. D. Xu, M. Jiang and Z. Tan, Acta Chem. Sin., 41, 570 (1983).

2. V. Sathyanarayanamoorthi, U. Ponnambalam, S. Gunasekar and V. Kannappan. J. Mol. Liq., 129181 (2006).

3. C. Alhambra, J. Corchado, M.L. Sanchez, J. Gao and J. Truhlar, J. Am. Chem. Soc., 122, 8197 (2000).

4. U. Rothlisberger, P. Carloni, K. Doclo and M. Parrinello, J. Biol. Inorg. Chem., 5, 236 (2000).

5. Q. Cui and M. Karplus, J. Am. Chem. Soc., 124, 3093 (2002).

6. V. Sathanarayanamoorthi, U. Ponnambalam, S. Gunasekar and V. Kannappan, J. Mol. Liq., 112, 157 (2004).

7. E. Cuhero, F.J. Lique, M. Orozeo and J.L. Gao, J. Phys. Chem. B, 107, 1664 (2003).

8. P. Minget, J.D. Thomson, C.J. Cramer and D.G. Truhlar, J. Phys. Chem. A, 106, 5160 (2002).

9. V. Sathayanarayanamoorthi, U. Ponnambalam, S. Gunasekar and V. Kannappan, J. Mol. Liq., 129, 181 (2006).

10. S. Mahalakshmi, V. Sathyanarayanamoorthi and V. Kannappan, J. Mol. Liquids, 139, 43 (2008)

11. M. Seefelder, M. Henlius, H. Qnast, W.D. Edwards, J.R. Armantront, R.V. Williams, C.J. Cramer, A.C. Goren, D.A. Hrovat and M.T. Borden, J. Org. Chem., 70, 3437 (2005).

12. J. Gao and X. Xia, Science, 258, 631 (1992).

13. J. Langlet, P. Claverie, J. Caillet and A. Pullman, J. Phys. Chem., 92, 1617 (1988).

14. R.A. Pierotti, J. Chem. Phys., 69, 281 (1965).
} 